\title{
A Study on Optimum Mixture Ratio of Reactive Powder Concrete
}

\author{
Mingyang Chen $(\mathbb{D})$ and Wenzhong Zheng $(\mathbb{D}$ \\ Department of Civil Engineering, Harbin Institute of Technology, Harbin, China \\ Correspondence should be addressed to Mingyang Chen; chenmy08@163.com
}

Received 21 June 2018; Revised 9 September 2018; Accepted 4 October 2018; Published 6 November 2018

Academic Editor: Shazim A. Memon

Copyright (c) 2018 Mingyang Chen and Wenzhong Zheng. This is an open access article distributed under the Creative Commons Attribution License, which permits unrestricted use, distribution, and reproduction in any medium, provided the original work is properly cited.

\begin{abstract}
To optimize the main components of reactive powder concrete (RPC) for various curing methods, based on the fluidity and compressive strength, an inclusive experimental research is conducted on 58 different mixture ratios. The results indicate that owing to the increase of the cement strength, the RPC fluidity decreases and the cement strength is not proportional to the compressive strength. The addition of the fly ash and the nano-microbead is an effective way to improve the fluidity, and it is required at the low W/B ratio. However, the influence of the SF grade on the strength and fluidity is almost negligible. By considering the fluidity, strength, and economy of RPC as crucial design factors, SF90 is suggested. The contribution of the steel fiber to the compressive strength cannot be ignored. The upper envelope value of the steel fibers is required for the structure to resist appropriately against the fire. According to the test results, the mixture ratio formula is proposed through considering the characters of different compositions and curing methods. The strength coefficient $k_{1}$ is introduced to verify the influence of the steel fiber content, and the parameters $f_{\mathrm{b}}, \alpha_{\mathrm{a}}$, and $\alpha_{\mathrm{b}}$ in the formula are reevaluated. A reasonably good agreement between the calculated strength and those obtained from the tests is reported, except for the case of W/B $=0.16$ with P.O.52.5 cement. The basic steps for preparations of different RPC strengths are given, which provide a valuable reference to choose appropriate raw materials and mixture ratio design for different strength values.
\end{abstract}

\section{Introduction}

Reactive powder concrete (RPC) [1] is a relatively new type of cement-based composite material successfully developed by Richard in 1993 with ultrahigh strength, good volume stability, and excellent durability [2]. On account of the fact that RPC has superior performance indicators, such as chloride ion permeability, anticarbonation, antifreeze-thaw resistance, and corrosion resistance $[3,4]$, it satisfies higher requirements for durability in marine engineering, chemical workshops, projects in the salt lake area, and other higherosion environments. Researchers have paid more attention on the components of RPC mixture, investigating the influence on the mechanism of compressive strength of RPC in terms of the substitution from silica fume to mineral flour or rice hull ash, variance of the water-to-binder ratio (W/B), optimization of raw material particle-size distribution, and different curing methods [5-8]. Until now, the preparation of RPC200 in the experiment is mature, and recently RPC was applied to practical projects such as high-speed railway bridges, industrial plant reconstruction, sidewalk boards, and nuclear waste storage facilities [9-15]. The issued national standard named as Reactive Powder Concrete in China (GB/T 31387-2015) [16] will accelerate the RPC researches and more engineering applications.

In this paper, we aim to provide a guide to optimise the preparation of different strength levels from RPC100 to RPC180, including the influential factors on the strength and fluidity, and accordingly setting up the mixture ratio formula for different RPC strengths. Section 2 introduces the details of the main components and properties, three curing methods, and details of 58 mixture ratios. Section 3 analyses the effect of cement grade, silica fume (SF) grade and content, the content of fly ash (FA), N-MB and steel fiber, $\mathrm{W} / \mathrm{B}$ ratio of $0.16 \sim 0.26$, and curing methods on the strength and fluidity of RPC. Ultrahigh strength exposes RPC to high risk of explosive spalling in fire. With the aim of reducing the potential danger, Section 4 refers to the formula of the upper 
envelope value $\left(\rho_{f \text {-up }}\right)$ and the average value $\left(\bar{\rho}_{f}\right)$ of steel fiber content by Chen et al. [17] and compares with the minimum steel fiber content by Reactive Powder Concrete (GB/T 31387-2015). According to the results obtained from the abovementioned researches, in Section 5, we will set up the mixture ratio formula taking the affecting factors into consideration on the RPC preparation which shares the same principle of normal concrete (NC). Finally, with results of some general observations, the recommendations for ongoing works are given in Section 6.

\section{Materials and Mixture Ratios}

Basic principles for preparation of high-performance RPC include elimination of coarse aggregates, optimization of the granular mixture, postset heat-treating, and incorporating small-sized steel fibers [1]. In this paper, RPC is prepared by the following components. (1) P.O.42.5 and P.O.52.5 ordinary Portland cement from Tangshan Jidong Co., Ltd. (2) SF of grade SF85, SF88, SF90, SF93, and SF97 from Shanghai Tiankai Co., Ltd., which are classified in accordance with the content of $\mathrm{SiO}_{2}$ and their detailed chemical compositions are listed in Table 1. (3) The grade I FA from Beijing. (4) Nanomicrobead (N-MB) with the average particle size of $1 / 20$ of the fly ash. It is widely used to replace FA in practice, to increase the fluidity and the strength of RPC, for its high compressive strength of the sphere exceeding $800 \mathrm{MPa}$ [14], and demands less water. (5) High-purity quartz sand with diameters in the range of $600 \sim 360 \mu \mathrm{m}$ and $360 \sim 180 \mu \mathrm{m}$, produced by Henan Green Source Environmental Protection Co., Ltd. in which the mass fraction of $\mathrm{SiO}_{2}$ exceeds 99.6\%. (6) Ultrafine and ultrashort copper wire microfibers produced by Changhong Steel Plant Co., Ltd in Anshan City, with the diameter of $0.20 \mathrm{~mm}$, length of $13 \mathrm{~mm}$, and tensile strength of $2850 \mathrm{MPa}$. All the material properties satisfy the Chinese standard.

The standard curing (C1), most frequently used for NC, is selected. In order to activate the volcanic ash activity, the steam curing $(\mathrm{C} 2)$ with $90^{\circ} \mathrm{C}$ steam in the tank and curing in the autoclaved reactor $(\mathrm{C} 3)$ with themaximum temperature of $200^{\circ} \mathrm{C}$ and the maximum pressure of $1.3 \mathrm{MPa}$ (Figures 1 and 2) are used. Fluidity of the mixture is measured by the cement mortar fluidity tester according to the jump table method. Compressive strength is tested by the TYE-3000B pressure testing machine, applying the average value of three cubic specimens with a side length of $70.7 \mathrm{~mm}$.

In order to examine the influence of the cement strength, $\mathrm{W} / \mathrm{B}$ ratio, curing methods, and contents of steel fiber, SF and FA, on the fluidity and compressive strength of RPC, six groups of experiments (G1-G6), which include 58 different mixture ratios, are carried out. G1 shows the effect brought by the cement strength change of P.O.42.5 and P.O.52.5, with the W/B of 0.16 and 0.20 . G2 indicates the change of the $\mathrm{W} / \mathrm{B}$ ratio from 0.16 to 0.26 under three curing methods. The effect of steel fiber content of 1\% 3\% under autoclave curing is indicated in G3, owing to the fact that it is the most economic ratio. The effect brought by the SF grade and its content can be discovered in G4. The effect brought by the fly ash content is shown in G5. G6 illustrates the effect brought
TABLE 1: Chemical composition of various SF.

\begin{tabular}{|c|c|c|c|c|c|}
\hline Item & SF85 & SF88 & SF90 & SF93 & SF97 \\
\hline $\mathrm{SiO}_{2}(\%)$ & 86.4 & 89.02 & 92.09 & 94.8 & 97.77 \\
\hline $\mathrm{K}_{2} \mathrm{O}(\%)$ & 1.34 & 1.32 & 1.12 & 0.63 & 0.26 \\
\hline $\mathrm{Na}_{2} \mathrm{O}(\%)$ & 0.52 & 0.52 & 0.42 & 0.35 & 0.29 \\
\hline $\begin{array}{l}\text { Loss on ignition } \\
\text { under } 750^{\circ} \mathrm{C}(\%)\end{array}$ & 1.87 & 1.8 & 6 & 0.9 & 0.8 \\
\hline Water content $(\%)$ & 0.41 & 0.41 & 0.4 & 0.43 & 0.41 \\
\hline Surface area $\left(\mathrm{m}^{2} / \mathrm{g}\right)$ & 18 & 18 & 19 & 19 & 19 \\
\hline Volume density $\left(\mathrm{kg} / \mathrm{m}^{3}\right)$ & \multicolumn{5}{|c|}{$\begin{array}{l}200 \sim 350 \text { (origin) } \\
600 \sim 700 \text { (condense) }\end{array}$} \\
\hline
\end{tabular}

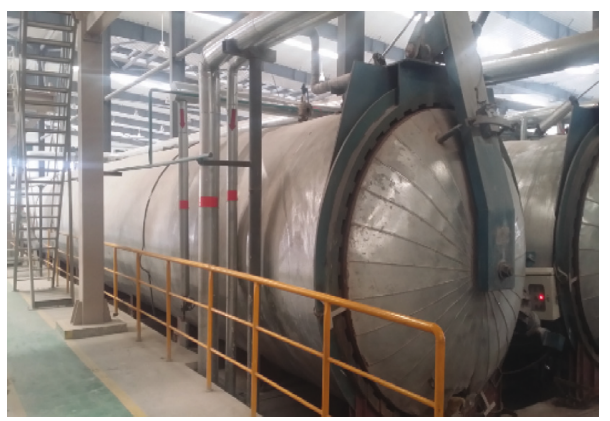

FIgURe 1: Autoclaved reactor.

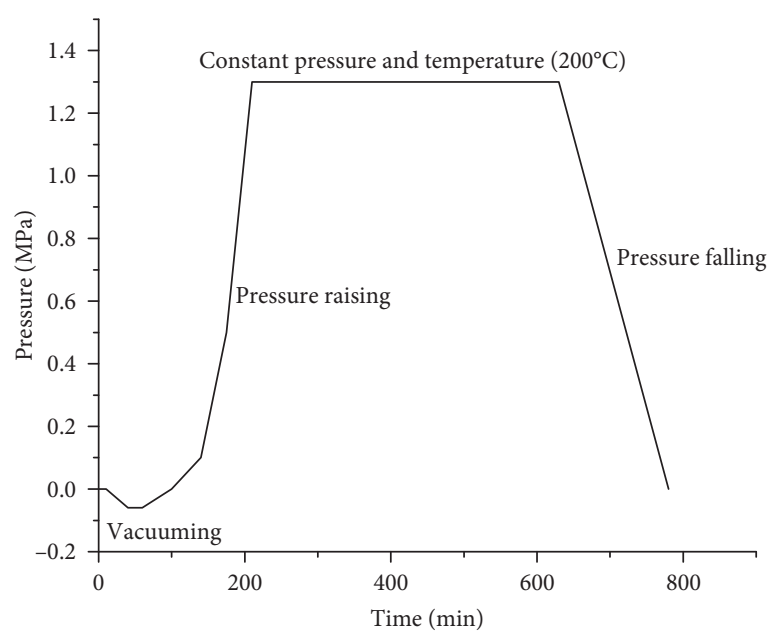

FIgURE 2: The time-history of temperature and pressure in the autoclaved reactor.

by the N-MB content. The details of the RPC mixture ratios, fluidity, and average cubic strength of the specimens are presented in Table 2.

\section{Analysis of Factors Influencing RPC Compressive Strength and Fluidity}

3.1. Cement Strength Grade (G1). It is apparent from data of G1 in Table 1 that, in the case of $\mathrm{W} / \mathrm{B}=0.16$, the fluidity of the RPC mixture decreases evidently from $136 \mathrm{~mm}$ to $123 \mathrm{~mm}$ after replacing P.O.42.5 with P.O.52.5 cement. It was difficult to cast when P.O.52.5 was replaced, and thus the 
TABLE 2: The mixture ratio of the specimens and the test results.

\begin{tabular}{|c|c|c|c|c|c|c|c|c|}
\hline Group & $\mathrm{W} / \mathrm{B}$ & FA & $\mathrm{N}-\mathrm{MB}$ & Fiber & Curing method & Fluidity $(\mathrm{mm})$ & Strength test/cal. (MPa) & Variation (\%) \\
\hline \multirow{4}{*}{ G1 } & 0.16 & 0.15 & 0.15 & - & $\mathrm{C} 3$ & 136 & $158 / 161$ & 1.9 \\
\hline & 0.16 & 0.3 & 0.15 & - & C3 & 123 & $164 / 177$ & 7.9 \\
\hline & 0.2 & 0.3 & - & - & $\mathrm{C} 3$ & 187 & $129 / 128$ & -0.8 \\
\hline & 0.2 & 0.3 & - & - & $\mathrm{C} 3$ & 182 & $143 / 141$ & -1.4 \\
\hline \multirow{24}{*}{ G2 } & 0.16 & 0.15 & 0.15 & - & $\mathrm{C} 1$ & 136 & $129 / 130$ & 0.8 \\
\hline & 0.17 & 0.3 & - & - & $\mathrm{C} 1$ & 145 & $126 / 123$ & -2.4 \\
\hline & 0.18 & 0.3 & - & - & $\mathrm{C} 1$ & 159 & $117 / 116$ & -0.9 \\
\hline & 0.19 & 0.3 & - & - & $\mathrm{C} 1$ & 172 & $108 / 109$ & 0.9 \\
\hline & 0.2 & 0.3 & - & - & $\mathrm{C} 1$ & 187 & $103 / 104$ & 1 \\
\hline & 0.22 & 0.3 & - & - & $\mathrm{C} 1$ & 209 & $95 / 94$ & -1.1 \\
\hline & 0.24 & 0.3 & - & - & $\mathrm{C} 1$ & 223 & $86 / 86$ & 0 \\
\hline & 0.26 & 0.3 & - & - & $\mathrm{C} 1$ & 237 & $77 / 79$ & 2.6 \\
\hline & 0.16 & 0.15 & 0.15 & - & $\mathrm{C} 2$ & 136 & $138 / 143$ & 3.6 \\
\hline & 0.17 & 0.3 & - & - & $\mathrm{C} 2$ & 145 & $136 / 134$ & -1.5 \\
\hline & 0.18 & 0.3 & - & - & $\mathrm{C} 2$ & 159 & $129 / 126$ & -2.3 \\
\hline & 0.19 & 0.3 & - & - & $\mathrm{C} 2$ & 172 & $122 / 120$ & -1.6 \\
\hline & 0.2 & 0.3 & - & - & $\mathrm{C} 2$ & 187 & $113 / 114$ & 0.9 \\
\hline & 0.22 & 0.3 & - & - & $\mathrm{C} 2$ & 209 & $106 / 103$ & -2.8 \\
\hline & 0.24 & 0.3 & - & - & $\mathrm{C} 2$ & 223 & $97 / 94$ & -3.1 \\
\hline & 0.26 & 0.3 & - & - & $\mathrm{C} 2$ & 237 & $86 / 87$ & 1.2 \\
\hline & 0.16 & 0.15 & 0.15 & - & $\mathrm{C} 3$ & 136 & $156 / 161$ & 3.2 \\
\hline & 0.17 & 0.3 & - & - & C3 & 145 & $153 / 151$ & -1.3 \\
\hline & 0.18 & 0.3 & - & - & C3 & 159 & $147 / 143$ & -2.7 \\
\hline & 0.19 & 0.3 & - & - & $\mathrm{C} 3$ & 172 & $139 / 135$ & -2.9 \\
\hline & 0.2 & 0.3 & - & - & C3 & 187 & $131 / 128$ & -2.3 \\
\hline & 0.22 & 0.3 & - & - & C3 & 209 & $120 / 116$ & -3.3 \\
\hline & 0.24 & 0.3 & - & - & C3 & 223 & $105 / 106$ & 1 \\
\hline & 0.26 & 0.3 & - & - & $\mathrm{C}$ & 237 & 98/98 & 0 \\
\hline \multirow{12}{*}{ G3 } & 0.16 & 0.15 & 0.15 & 1 & $\mathrm{C}$ & 130 & $185 / 186$ & 0.5 \\
\hline & 0.16 & 0.15 & 0.15 & 2 & $\mathrm{C} 3$ & 127 & $197 / 199$ & 1 \\
\hline & 0.16 & 0.15 & 0.15 & 3 & $\mathrm{C} 3$ & 119 & $215 / 211$ & -1.9 \\
\hline & 0.18 & 0.3 & - & 1 & C3 & 148 & $173 / 165$ & -4.6 \\
\hline & 0.18 & 0.3 & - & 2 & $\mathrm{C} 3$ & 142 & $181 / 177$ & -2.2 \\
\hline & 0.18 & 0.3 & - & 3 & $\mathrm{C} 3$ & 138 & $193 / 187$ & -3.1 \\
\hline & 0.22 & 0.3 & - & 1 & C3 & 206 & $138 / 135$ & -2.2 \\
\hline & 0.22 & 0.3 & - & 2 & C3 & 201 & $150 / 144$ & -4 \\
\hline & 0.22 & 0.3 & - & 3 & C3 & 194 & $156 / 152$ & -2.6 \\
\hline & 0.26 & 0.3 & - & 1 & $\mathrm{C} 3$ & 236 & $110 / 114$ & 3.6 \\
\hline & 0.26 & 0.3 & - & 2 & C3 & 233 & $118 / 121$ & 2.5 \\
\hline & 0.26 & 0.3 & - & 3 & $\mathrm{C} 3$ & 229 & $123 / 128$ & 4.1 \\
\hline \multirow{5}{*}{ G4 } & 0.18 & 0.3 & - & 2 & C3 & 147 & $175 / 177$ & 1.1 \\
\hline & 0.18 & 0.3 & - & 2 & $\mathrm{C} 3$ & 154 & $178 / 177$ & -0.6 \\
\hline & 0.18 & 0.3 & - & 2 & $\mathrm{C} 3$ & 159 & $183 / 177$ & -3.3 \\
\hline & 0.18 & 0.3 & - & 2 & $\mathrm{C} 3$ & 163 & $181 / 177$ & -2.2 \\
\hline & 0.18 & 0.3 & - & 2 & $\mathrm{C} 3$ & 167 & $180 / 177$ & -1.7 \\
\hline \multirow{8}{*}{ G5 } & 0.18 & 0.15 & - & 2 & C3 & 137 & $182 / 177$ & -2.7 \\
\hline & 0.18 & 0.2 & - & 2 & C3 & 142 & $187 / 177$ & -5.3 \\
\hline & 0.18 & 0.25 & - & 2 & $\mathrm{C} 3$ & 153 & $184 / 177$ & -3.8 \\
\hline & 0.18 & 0.3 & - & 2 & C3 & 159 & $180 / 177$ & -1.7 \\
\hline & 0.2 & 0.15 & - & 2 & C3 & 161 & $164 / 159$ & -3 \\
\hline & 0.2 & 0.2 & - & 2 & C3 & 173 & $159 / 159$ & 0 \\
\hline & 0.2 & 0.25 & - & 2 & C3 & 179 & $155 / 159$ & 2.6 \\
\hline & 0.2 & 0.3 & - & 2 & $\mathrm{C} 3$ & 187 & $152 / 159$ & 4.6 \\
\hline \multirow{5}{*}{ G6 } & 0.16 & 0.3 & - & 2 & C3 & 122 & $189 / 199$ & 5.3 \\
\hline & 0.16 & 0.225 & 0.075 & 2 & $\mathrm{C} 3$ & 129 & $195 / 199$ & 2.1 \\
\hline & 0.16 & 0.15 & 0.15 & 2 & C3 & 136 & $200 / 199$ & -0.5 \\
\hline & 0.16 & 0.075 & 0.225 & 2 & $\mathrm{C}$ & 143 & $207 / 199$ & -3.9 \\
\hline & 0.16 & 0 & 0.3 & 2 & $\mathrm{C}$ & 141 & $209 / 199$ & -4.8 \\
\hline
\end{tabular}

Note. The steel fiber ratio is based on RPC volume, and the ratio of other components is based on cement mass. (2) The contents of silica fume and quartz sand keep the same as SF content is 0.3, and quartz sand is 1.2. (3) P.O.42.5 is used in G2 G6. (4) SF90 is used in G1 G3 and G6. 
casting quality becomes poor. It is due to this fact that the cement fineness decreases by increasing the strength of the cement. Simultaneously, the needed water increases. Due to the poor casting quality, the RPC strength using P.O.52.5 is merely $4 \%$ higher than that of P.O.42.5 for the case of W/B = 0.16 .

In the case of the W/B being 0.2 , the fluidity of the RPC is sufficient and the fluidity would reduce from $187 \mathrm{~mm}$ to $182 \mathrm{~mm}$ after replacing P.O.42.5 with P.O.52.5 cement. However, the RPC's strength on the basis of P.O.52.5 was about $10.9 \%$ higher than that based on P.O.42.5. But according to "Specification for Design of Mix Ratio of Ordinary Concrete" [20] in China, the NC strength is proportional to the cement strength, which means that the concrete strength based on P.O.52.5 should be 23.55\% higher than that based on P.O.42.5. So it is different in the cases of applying RPC and NC.

3.2. W/B Ratio and Curing Methods (G2). Figure 3 shows that the RPC strength in terms of the W/B ratio varies from 0.16 to 0.26 under standard curing, steam curing, and autoclave curing. As shown in Figure 2 and G2 in Table 1, by increasing the $\mathrm{W} / \mathrm{B}$ from 0.16 to 0.26 , the fluidity grows from $136 \mathrm{~mm}$ to $237 \mathrm{~mm}$, while the strength decreases from $129 \mathrm{MPa}$ to $77 \mathrm{MPa}$ under standard curing. Meanwhile, under the steam and autoclave curing conditions, it would decrease from $138 \mathrm{MPa}$ to $86 \mathrm{MPa}$, and from $156 \mathrm{MPa}$ to $98 \mathrm{MPa}$, respectively. Through conducting the research using the same W/B ratio, the RPC strength increases approximately by $11 \%$ under the steam curing, while the obtained strength under the autoclave curing is about $25 \%$ higher than under the standard curing. It is believed that the high-temperature curing, such as steam and autoclave, contributes to activate the volcanic ash activity by SF and FA in RPC components and yields a large increase in compressive strength in a relatively short time.

The fitting between the RPC strength and the W/B ratio shows that the strength of the RPC is inversely proportional to the $\mathrm{W} / \mathrm{B}$ ratio. By comparing the fitted curves with the experimental data, it is found that most of the experimentally observed data have a little deviation from the fitted values. However, for the case of $\mathrm{W} / \mathrm{B}=0.16$, the observed strengths from the test are lower than the fitted curves, and the deviation is larger. This is mainly due to this fact that, in the case of $\mathrm{W} / \mathrm{B}=0.16$, the fluidity is $136 \mathrm{~mm}$ and the RPC mixture has hardened, and it causes difficulty for the bubbles to be expelled. Consequently, the casting quality cannot be ensured, in which the compressive strength is affected [7].

3.3. Steel Fiber Content (G3). Owing to the fact that the pore between aggregates in NC is significantly larger than the fiber diameter (which is about $0.2 \mathrm{~mm}$ ), effect of the increasing steel fibers on the strength is not apparent. However, for the RPC, the maximum diameter of the coarse aggregate quartz sands is only $0.6 \mathrm{~mm}$, the internal pores are very tiny such that their size are nearly equal to the fiber's diameter, the steel fibers are closely bound to the mortar and the coarse aggregate, the reinforcement, toughening, and

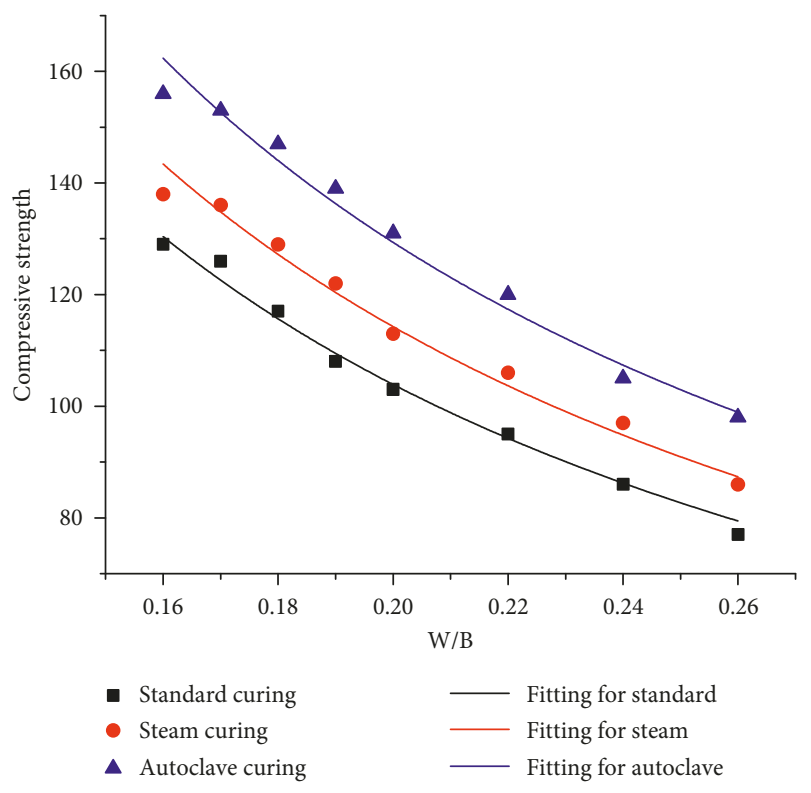

FIgURE 3: The experimental plots of the W/B in terms of the compressive strength for different curing methods.

cracking resistance of steel fiber to the RPC matrix are obvious, and the contribution of the steel fiber to the compressive strength cannot be ignored [6]. The fibers improve the tensile strength of RPC and also make it possible to obtain the required level of ductility [1].

Data of G3 in Table 1 show that, with an increase of the steel fiber content, the fluidity of the RPC decreases while the strength increases. However, when the $\mathrm{W} / \mathrm{B}$ reaches $0.16 \sim 0.18$, the internal friction force of the RPC mixed with the steel fiber would apparently increase, and such an effect on the fluidity of the RPC is apparent; for the W/B in the range of $0.20-0.26$, the fluidity of the RPC is sufficient, and adding steel fiber do not affect on the RPC fluidity significantly. Furthermore, by the addition of $1 \%$ steel fiber, the strength increases significantly, which is $12 \% \sim 19 \%$ higher than that of no steel fiber; by adding $3 \%$ steel fiber in the case of the $\mathrm{W} / \mathrm{B}=$ 0.16 , the strength raises about $38 \%$, while it increases only $26 \%$ for $\mathrm{W} / \mathrm{B}=0.26$. Consequently, with the increase of the $\mathrm{W} / \mathrm{B}$, the influence of the steel fiber on the compressive strength decays. The reason of this is that, with the growth of the $\mathrm{W} / \mathrm{B}$, the fluidity increases, the internal porosity raises, and the density reduces, which leads to the reduction of the enclosing force of the RPC slurry to the steel fibers. Therefore, the suggested fiber content is below $2 \%$, which will maintain a good balance between RPC strength, fluidity, and economy.

3.4. SF Grade (G4). Most of the researchers have tried to adopt SF in RPC preparation from Elkem Co., Ltd in Norway, which has provided excellent quality and stable performance to obtain higher strength. The preparation of the SF from abroad requires higher investment, and it is not suitable for extensive application in the local projects.

Therefore, five grades (SF85/SF88/SF90/SF93/SF97) are selected for the test. According to the results of G4 in Table 1, the fluidity of SF97 is approximately $11 \%$ higher than that of 
SF85, which is primarily due to the decrease of injurious impurities of carbon and alkalis, as well as the reduction of the required water by increasing of $\mathrm{SiO}_{2}$. However, the fluidity of SF85 meets the RPC pouring condition. As the SF grade grows, the RPC strength decreases slightly, and the range of change is barely $3 \%$, so the influence of the SF grade on the RPC strength is almost negligible. The SF grade is classified according to the content of $\mathrm{SiO}_{2}$. The actual contents of $\mathrm{SiO}_{2}$ in SF97 and SF85 in order are about $97.77 \%$ and $86.4 \%$, which show an increase of about $12 \%$. However, as the $\mathrm{SiO}_{2}$ purity increases, the production process will be changed and the difficulty increases, which leads to a higher cost since the price of SF97 is approximately 5 times of the price of SF85. Therefore, by taking into account fluidity, strength, and economy of RPC as the major factors, SF90 is suggested.

3.5. FA Content (G5). Research has shown that FA can further improve the fluidity and ease of the fresh slurry and then reduce the viscosity and bubbles introduced in stirring and vibration due to high viscosity, thus enhancing the compactness of the mixture. Therefore, FA plays a significant role in improving fluidity of the RPC with a low W/B. Data of G5 in Table 1 show the fluidity and strength of the RPC for $\mathrm{W} / \mathrm{B}=0.18$ and 0.2 , and the content of the FA varies from 0.15 to 0.3 . The given test data demonstrate that, for $\mathrm{W} / \mathrm{B}$ lower than 0.18 , adding FA can improve the fluidity and the strength; when the W/B is greater than 0.18 with enough liquid, adding FA will reduce the compressive strength. Since the price of the FA is lower than that of the cement, the inclusion of the FA will be helpful in reducing the preparation cost of the RPC.

3.6. N-MB Content (G6). Feng Naiqian studied the physical properties of N-MB. It was reported that N-MB is a globular and smooth vitreous body, while N-MB would be very beneficial in preparation of high-performance and ultrahighperformance concrete [18]. According to the data of G6 in Table 1 , when the W/B ratio is 0.16 , the fluidity of the RPC is not obviously improved by growing the FA; however, its strength weakened. Therefore, with the increase of the N-MB substitution, the fluidity increases and the casting effect is apparently improved obviously. When the content of both $\mathrm{N}-\mathrm{MB}$ and FA is 0.15 , the fluidity is more than $130 \mathrm{~mm}$, which met the requirements of pouring. Since the density of the $\mathrm{N}-\mathrm{MB}$ is greater than that of the FA, the density of the RPC improves while the fluidity grows by increasing of the N-MB. In fact, the RPC strength increases about $11 \%$ by replacing all the FA with the N-MB. However, because of this fact that the price of the N-MB is 3 times of the FA price, it is suggested that, in the case of $\mathrm{W} / \mathrm{B}=0.16$, the mass fraction of both $\mathrm{N}-\mathrm{MB}$ and FA should be 0.15 , and the RPC strength is approximately $6 \%$ higher than the case with only $\mathrm{FA}=0.3$.

\section{Steel Fiber Content to Resist the Explosive Spalling of RPC}

The inclusion of fibers improves the tensile strength of the RPC and also makes it possible to obtain the required level of the ductility. Hence, the code of Reactive Powder Concrete (GB/T 31387-2015) suggests the minimum fiber ratio to be $0.7 \% \sim 2.5 \%$ for RPC100 RPC180, which is in the economic optimum range of $2 \%$ as suggested by Richard and Cheyrezy [1].

Since fire is one of the severest hazards to the buildings and structures, the fire resistance should be considered for their designs. One of the key issues for the fire resistance design is to avoid explosive spalling. It is demonstrated that as the concrete strength increases, the microstructure becomes denser, the permeability decreases, and thereby, the probability of the explosive spalling in fire becomes higher. In other words, there exists a high risk of explosive spalling in fire situations for RPC with ultrahigh strength. According to the performed research work by Zheng et al. [19], single or mixed polypropylene (PP) fibers and steel fibers can be exploited to prevent the RPC from the fire spalling. Chen et al. [17] collected the research data of the steel fiber ratio to prevent explosive spalling in concretes whose compressive strengths are in the range of $40-170 \mathrm{MPa}$. For preventing explosive spalling, the relationship between the amount of steel fibers and the concrete compressive strength was explained. Equation (1) presents the upper envelope value $\left(\rho_{f \text {-up }}\right)$ of the steel fiber content to prevent explosive spalling by the collected research data, and Equation (2) displays its average value $\left(\bar{\rho}_{f}\right)$, for the concrete strength in the range of 40-170 MPa:

$$
\begin{gathered}
\rho_{f-\mathrm{up}}=0.0017 \exp \left(\frac{f_{\mathrm{cu}}}{23}\right)+1.05, \\
\bar{\rho}_{f}=0.001 \exp \left(\frac{f_{\mathrm{cu}}}{23}\right)+0.80 .
\end{gathered}
$$

Table 3 shows the minimum steel fiber content given by Reactive Powder Concrete (GB/T 31387-2015) and the value calculated by Equations (1) and (2). Based on Table 3, the upper envelope value by Equation (1) is higher than the minimum value by the code, so it does not ensure the safety for the structures whose fire resistance should be checked when adopting the fiber content suggested by the code. But the average value by Equation (2) is smaller than the suggested minimum value by the code when the strength is in the range of 120 160 MPa. So, in order to guarantee the structure safety against fire, it is suggested to use Equation (1) for fiber content calculations before a more refined value could be proposed by more research on the fire resistance of the RPC.

\section{RPC Mixture Ratio Design}

5.1. The Formula of Mixture Ratio Setup. The formula of the $\mathrm{NC}$ mix proportion by Bowromi is widely used. Owing to the fact that the RPC is cement-based composite material as NC [1], we try to amend the NC mix proportion formula considering the RPC characters for different compositions and special preparation processes. New strength coefficient $k_{1}$ is introduced to consider the influence of the steel fibers content on the RPC strength, and the parameters $f_{\mathrm{b}}, \alpha_{\mathrm{a}}$, and 
TABLE 3: A comparison between the fiber content by the code and the values of $\rho_{f \text {-up }}$ and $\bar{\rho}_{f}$.

\begin{tabular}{lcccc}
\hline RPC grade & $f_{\mathrm{cu}}^{k}$ & Minimum value by code & $\rho_{f \text {-up }}$ & $\bar{\rho}_{f}$ \\
\hline RPC100 & 100 & 0.70 & 1.18 & 0.88 \\
RPC120 & 120 & 1.20 & 1.36 & 0.98 \\
RPC140 & 140 & 1.70 & 1.80 & 1.24 \\
RPC160 & 160 & 2.00 & 2.83 & 1.85 \\
RPC180 & 180 & 2.50 & 5.31 & 3.31 \\
\hline
\end{tabular}

$\alpha_{\mathrm{b}}$ in the formula can be revaluated by the test results in Section 3. The proposed formula is as follows:

$$
f_{\mathrm{cu}, 0}=k_{1}\left(\frac{\alpha_{\mathrm{a}} f_{\mathrm{b}}}{W / B}-\alpha_{\mathrm{a}} \alpha_{\mathrm{b}} f_{\mathrm{b}}\right) .
$$

For the cement type P.O.42.5, $f_{\mathrm{b}}$ is equal to 49.3 according to the suggested formula by the code, namely, $\gamma_{\mathrm{c}} \times f_{\mathrm{ce}, \mathrm{g}}$. From Section 3.1, the RPC strength with P.O.52.5 cement is approximately $10.9 \%$ higher than that with $\mathrm{P}$. O.42.5, which is not proportional to the cement strength. For instance, $f_{\mathrm{b}}$ resulted in 54.2 under condition of applying $\mathrm{P}$. O.52.5.

Unlike the NC, the postset heat-treating is required to enhance development of microstructures within the RPC, and therefore, the steam curing and autoclave curing are mostly implemented for the RPC. $\alpha_{\mathrm{a}}$ and $\alpha_{\mathrm{b}}$ for the three curing methods are revalued by using Figure 2, which are also presented in Table 4. From the data in Table 4, it can be discovered that the regression coefficient $\alpha_{\mathrm{a}}$ of the RPC under standard curing and steam curing is less than that of the NC. This is consistent with the test results which display that the RPC test value is smaller than that proposed by the code.

According to Section 3.3, the strength magnification coefficient $\left(k_{1}\right)$ for different steel fiber contents is provided in Table 5. We found that the slop between the fiber content and the RPC strength decreases. It implies that, for the fiber contents higher than $3 \%$, the steel fiber content has a trivial influence on the strength of the RPC. Because of this fact, most researchers suggest that the economic optimum value of the steel fibers should be considered below 2\% or $155 \mathrm{~kg} / \mathrm{m}^{3}$.

According to the abovementioned parameter values, the calculated values of strength based on Equation (3) are given in Table 1; the calculated strength and the test data are also listed. It is demonstrated that, in the case of $\mathrm{W} / \mathrm{B}=0.16$ with the cement of P.O.52.5, the deviation rate reaches $8 \%$. And the deviation rates of all others are within the engineering allowable error range of $\pm 5 \%$. Actually, the calculated values by the proposed formulations are in a good agreement with the experimentally obtained results.

5.2. The Suggested Step for Preparation of Different RPC Grades. According to the required RPC design strength, the minimum steel fiber content by the code is used for the structures without consideration of the fire resistance, and otherwise, the upper envelope value by Equation (1) should be employed. Thereafter, the fiber content is confirmed, and then the $k_{1}$ value is extracted from Table 5 . Next, we proceed
TABLE 4: The values of $\alpha_{\mathrm{a}}$ and $\alpha_{\mathrm{b}}$ of the RPC under different curing methods.

\begin{tabular}{lcccc}
\hline $\begin{array}{l}\text { Curing } \\
\text { method }\end{array}$ & NC & $\begin{array}{c}\text { Standard } \\
\text { curing }\end{array}$ & $\begin{array}{c}\text { Steam } \\
\text { curing }\end{array}$ & $\begin{array}{c}\text { Autoclave } \\
\text { curing }\end{array}$ \\
\hline$\alpha_{\mathrm{a}}$ & 0.53 & 0.43 & 0.47 & 0.54 \\
$\alpha_{\mathrm{b}}$ & 0.2 & 0.1 & 0.1 & 0.1 \\
\hline
\end{tabular}

TABLE 5: The strength magnification coefficient $\left(k_{1}\right)$ for different fiber ratios.

\begin{tabular}{lccc}
\hline Steel fiber content & $1 \%$ & $2 \%$ & $3 \%$ \\
\hline$k_{1}$ & 1.16 & 1.24 & 1.31 \\
\hline
\end{tabular}

in determining the regression coefficients $\alpha_{\mathrm{a}}$ and $\alpha_{\mathrm{b}}$ according to the curing method by using Table 4. After a simple transformation of Equation (3), the W/B can be obtained from Equation (4). For the case of the W/B lower than 0.2 , some FA can be added to improve the fluidity. When the FA content reaches 0.3 and the fluidity fails to satisfy the casting request, the $\mathrm{N}-\mathrm{MB}$ can be partially used as a replacement of the FA, and thus, enhancing the RPC fluidity:

$$
\frac{W}{B}=\frac{k_{1} \alpha_{\mathrm{a}} f_{\mathrm{b}}}{f_{\mathrm{cu}, 0}+k_{1} \alpha_{\mathrm{a}} \alpha_{\mathrm{b}} f_{\mathrm{b}}} .
$$

\section{Conclusions and Future Works}

The following conclusions can be obtained from the performed experimental and the given analyses:

(1) RPC is a cement-based composite material, complying with $\mathrm{W} / \mathrm{B}$ ratio rule and water-demand rule. The W/B ratio, the steel fiber content, and the curing method play a key role in the RPC strength. Both FA and N-MB help us to improve the RPC fluidity, and application usage of the SF90 grades in the RPC leads to an economic optimum design.

(2) RPC has a very compact microstructure and so the probability of spalling at high temperatures grows. Generally, the suggested minimum value by the code is smaller than the upper envelope value according to Equation (1). In order to guarantee the structure safety in the fire conditions, it is suggested to exploit formula (1) for fiber content calculation before the accurate value will be obtained by more research on fire resistance of RPC.

(3) According to the test results, the widely used Equation (3) of the NC mixture ratio by Bowromi is adopted, and the parameters $k_{1}, f_{\mathrm{b}}, \alpha_{\mathrm{a}}$, and $\alpha_{\mathrm{b}}$ are recalculated to consider the RPC characters. This study is expected to apply to the mix proportion design of the RPC by considering different curing methods and various steel fiber contents. Most of the calculated strength values by this formula are in a good agreement with experiments. The procedure 
of the RPC mixing is given, which can be used to instruct the RPC preparation.

(4) More mix proportion tests are needed to deal with the accuracy of the parameters. Actually, more studies or experiments should be conducted to analyse the mechanical behaviour of the RPC with different materials made in different areas. Researches on fire resistance are required before the RPC could be exploited in large scales.

\section{Data Availability}

The data used to support the findings of this study are available from the corresponding author upon request.

\section{Conflicts of Interest}

The authors declare that there are no conflicts of interest regarding the publication of this paper.

\section{Acknowledgments}

The authors would like to acknowledge the support provided by the National Natural Science Foundation of China (no. 51678190) for partially funding this research and thank all the staff and technicians in the lab for their kind assistance during the tests.

\section{References}

[1] P. Richard and M. Cheyrezy, "Composition of reactive powder concretes," Cement and Concrete Research, vol. 25, no. 7, pp. 1501-1511, 1995.

[2] P. Richard and M. Cheyrezy, "Reactive powder concretes with high ductility and 200-800 MPa compressive strength," ACI Special Publication, vol. 144, pp. 507-518, 1994.

[3] H. Yazıcı, M. Y. Yardımcı, H. Yiğiter, S. Aydın, and S. Türkel, "Mechanical properties of reactive powder concrete containing high volumes of ground granulated blast furnace slag," Cement and Concrete Composite, vol. 32, no. 8, pp. 639-648, 2010.

[4] V. T. A. Van, C. Rößler, D. D. Bui, and H. M. Ludwig, "Rice husk ash as both pozzolanic admixture and internal curing agent in ultra-high performance concrete," Cement and Concrete Composites, vol. 53, pp. 270-278, 2014.

[5] W. Zheng and L. Li, "Preparation and mix proportion calculation of reactive powder concrete," Journal of Hunan University (Science), vol. 36, no. 2, pp. 13-17, 2009.

[6] F. He and Z. Huang, "Study on the effect of materials on RPC strength," Journal of Hunan University (Science), vol. 28, no. 2, pp. 89-94, 2001.

[7] G. Yan, G. Yan, and M. An, "Experimental study on $200 \mathrm{MPa}$ reactive powder concrete," Journal of the China Railway Society, vol. 26, no. 2, pp. 116-119, 2004.

[8] W. Zheng and X. Y. Lv, "Literature review of reactive powder concrete," Journal of Building Structures, vol. 36, no. 10, pp. 44-58, 2015.

[9] P. Y. Blais and M. Couture, "Prestressed pedestrian bridgeworld's first reactive powder concrete structure," PCI Journal, vol. 44, no. 5, pp. 60-71, 1999.

[10] V. Candrlic, J. Bleiziffer, and A. Mandic, "Bakar bridge in reactive powder concrete," in Proceedings of Third
International Conference on Arch Bridge, pp. 695-700, Paris, France, 2001.

[11] B. Cavill and G. Chrigwin, "The world's first ductal road bridge shepherds gully creek bridge, NSW," in Proceedings of CIA 21st Biennial Conference, pp. 1-11, Brisbane, Australia, July 2003.

[12] M. Behloul and K. C. Lee, "Ductal ${ }^{\circledR}$ seonyu footbridge," Structural Concrete, vol. 4, no. 4, pp. 195-201, 2003.

[13] P. Mazzacane, R. Ricciotti, G. Lamoureux et al., "Roofing of the Stade Jean Bouin in UHPFRC," in Proceedings of International Symposium on Ultra-High Performance FibreReinforced Concrete, pp. 59-68, RILEM Publications, Marseille, France, 2013.

[14] H. Musha, H. Ohkuma, and T. Kitamura, "Innovative UFC structures in Japan," in Proceedings of International Symposium on Ultra-High Performance Fibre-Reinforced Concrete, pp. 17-26, RILEM Publications, Marseille, France, October 2013.

[15] P. Yu, "The design introduction of ancillary facilities in the railway bridges of Harbin to Dalian," Journal of Shanxi Architecture, vol. 36, no. 12, pp. 309-311, 2010.

[16] China Architecture \& Building Press, Reactive Powder Concrete (GB/T 31387-2015), China Architecture \& Building Press, Beijing, China, 2011.

[17] M. Chen, X. Hou, and W. Zheng, "Review and analysis on spalling critical temperature of concrete and Fibres dosage to prevent spalling at elevated temperatures," Journal of Building Structure, vol. 38, no. 1, pp. 75-80, 2017.

[18] N. Feng and H. Li, "Characteristics and applications of nano micro-bead (N-MB)," Journal of Concrete and Cement Products, vol. 37, no. 5, pp. 01-03, 2010.

[19] W. Zheng, X. Hou, and K. Yan, Fire Resistance of Prestressed Concrete and its Fire Safety Design, Harbin Institute of Technology Press, Harbin, China, 2012.

[20] China Architecture \& Building Press, Technical Specification for Mix Proportion Design of Ordinary Concrete (JGJ55-2011), China Architecture \& Building Press, Beijing, China, 2011. 


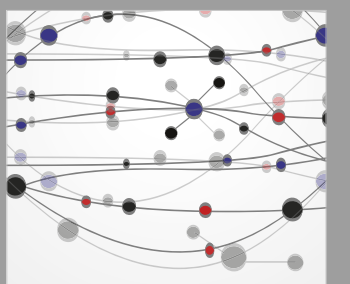

The Scientific World Journal
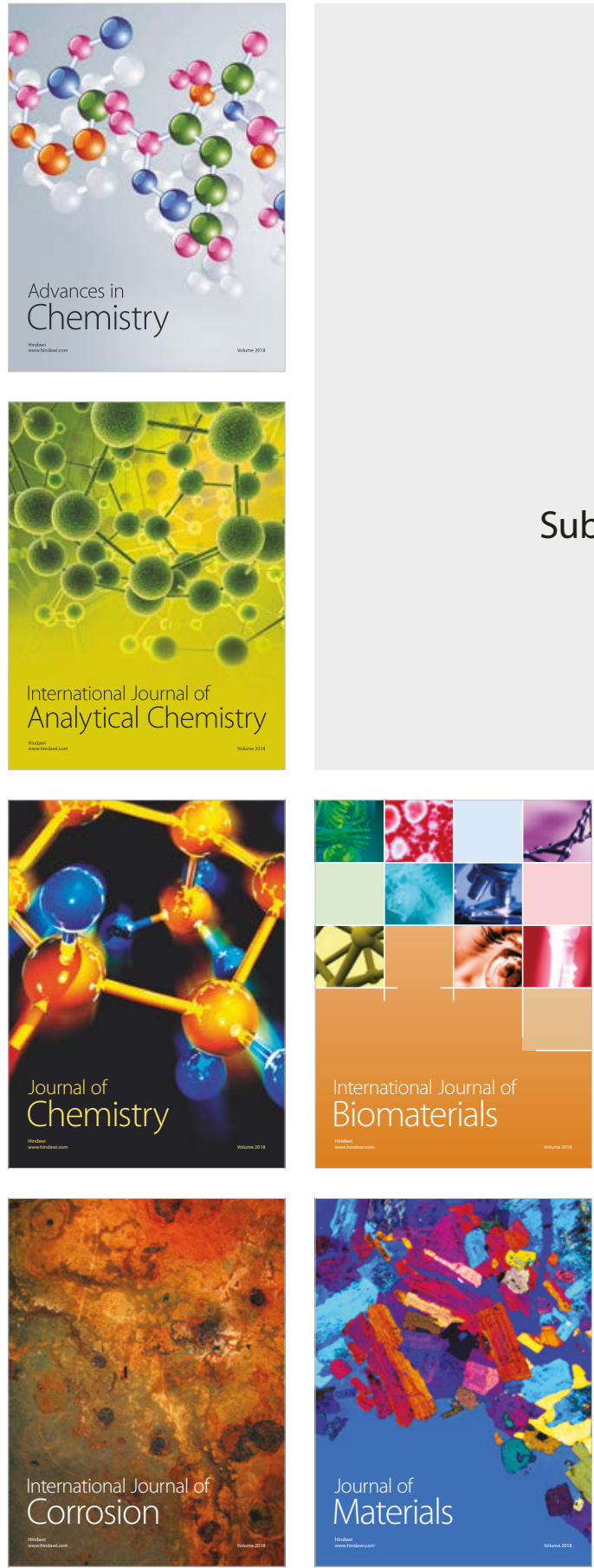

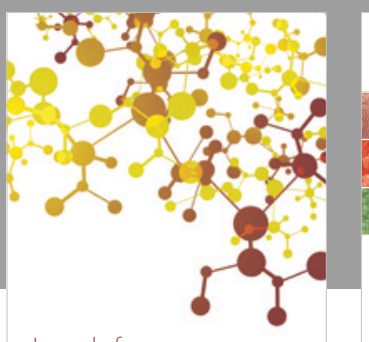

Journal of

Applied Chemistry
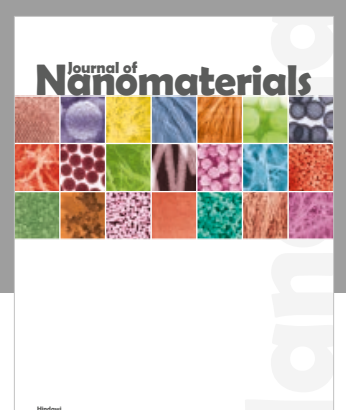

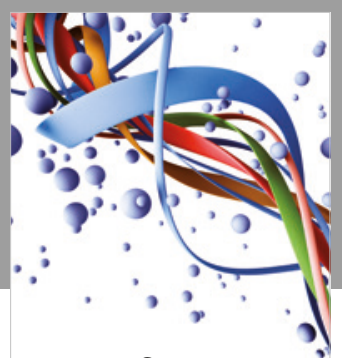

Scientifica

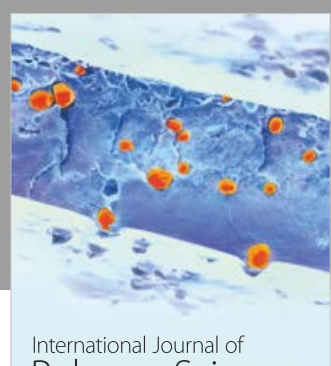

Polymer Science

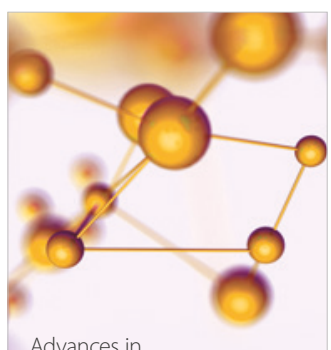

Physical Chemistry
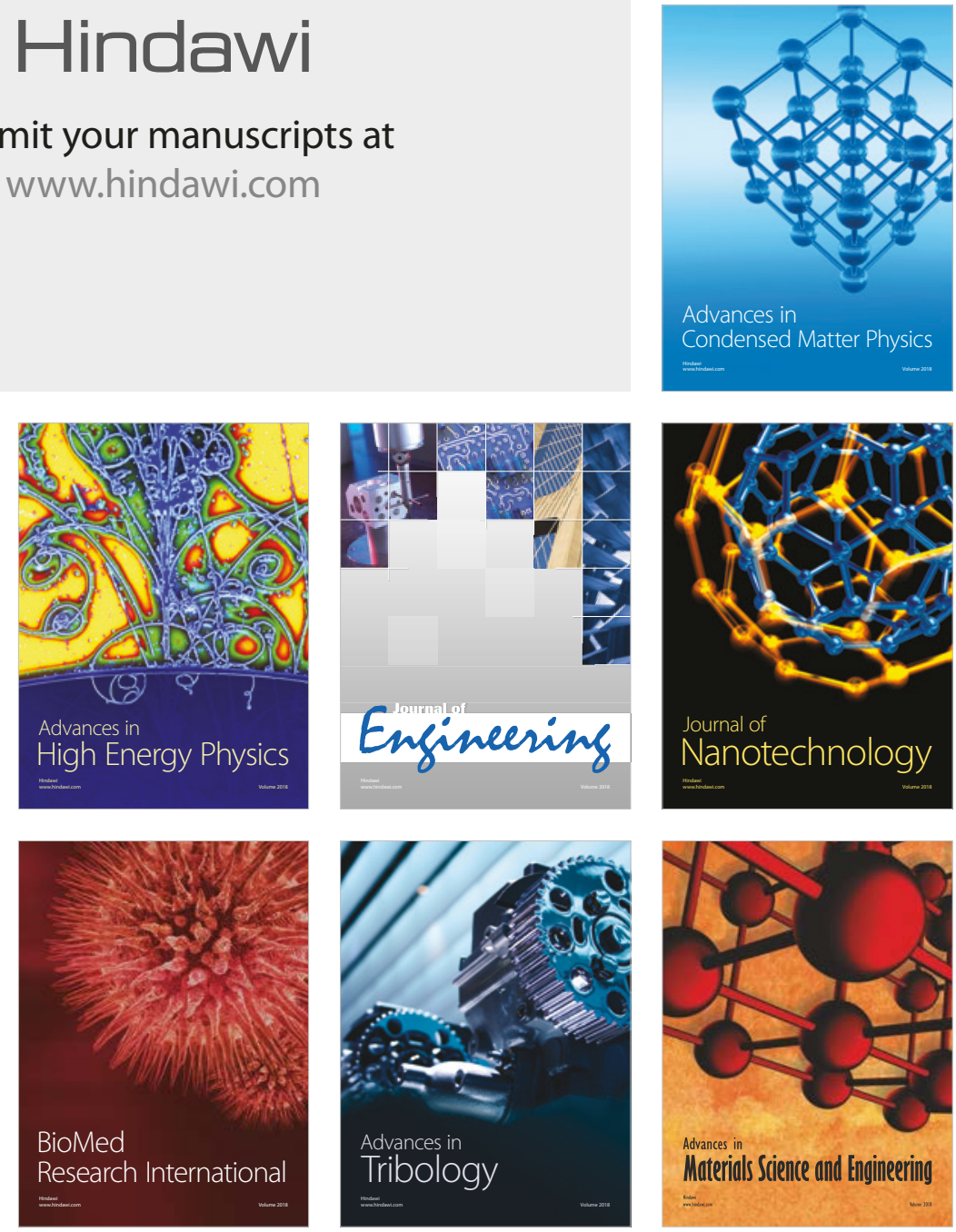